Cite this: Phys. Chem. Chem. Phys., 2013, 15, 8629

Received 21st December 2012, Accepted 25th April 2013

DOI: $10.1039 / \mathrm{c} 3 \mathrm{cp} 44638 \mathrm{~g}$

www.rsc.org/pccp

\section{Synchrotron high energy X-ray methods coupled to phase sensitive analysis to characterize aging of solid catalysts with enhanced sensitivity}

\author{
Davide Ferri, ${ }^{\text {ab }}$ Mark A. Newton, ${ }^{\mathrm{c}}$ Marco Di Michiel, ${ }^{\mathrm{c}}$ Songhak Yoon, ${ }^{\mathrm{b}}$

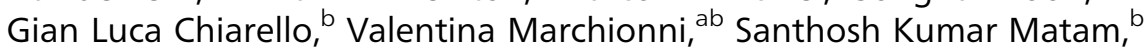 \\ Myriam H. Aguirre, $\dagger^{\mathrm{b}}$ Anke Weidenkaff, ${ }^{\mathrm{b}}$ Fei Wen ${ }^{\mathrm{d}}$ and Jürgen Gieshoff ${ }^{d}$
}

\begin{abstract}
X-ray absorption spectroscopy and X-ray diffraction are suitable probes of the chemical state of a catalyst under working conditions but are limited to bulk information. Here we show in two case studies related to hydrothermal aging and chemical modification of model automotive catalysts that enhanced detailed information of structural changes can be obtained when the two methods are combined with a concentration modulated excitation (CME) approach and phase sensitive detection (PSD). The catalysts are subject to a modulation experiment consisting of the periodic variation of the gas feed composition to the catalyst and the time-resolved data are additionally treated by PSD. In the case of a $2 \mathrm{wt} \% \mathrm{Rh} / \mathrm{Al}_{2} \mathrm{O}_{3}$ catalyst, a very small fraction (ca. $2 \%$ ) of Rh remaining exposed at the alumina surface after hydrothermal aging at $1273 \mathrm{~K}$ can be detected by PSD. This Rh is sensitive to the red-ox oscillations of the experiment and is likely responsible for the observed catalytic activity and selectivity during $\mathrm{NO}$ reduction by $\mathrm{CO}$. In the case of a $1.6 \mathrm{wt} \% \mathrm{Pd} / \mathrm{Al}_{2} \mathrm{O}_{3}-\mathrm{Ce}_{1-x} \mathrm{Zr}_{x} \mathrm{O}_{2}$ catalyst, preliminary results of $\mathrm{CME}-\mathrm{XRD}$ demonstrate that access to the kinetics of the whole material at work can be obtained. Both the red-ox processes involving the oxygen storage support and the $\mathrm{Pd}$ component can be followed with great precision. PSD enables the differentiation between $\mathrm{Pd}$ deposited on $\mathrm{Al}_{2} \mathrm{O}_{3}$ or on $\mathrm{Ce}_{1-x} \mathrm{Zr}_{x} \mathrm{O}_{2}$. Modification of the catalyst by phosphorous clearly induces loss of the structural dynamics required for oxygen storage capacity that is provided by the $\mathrm{Ce}^{4+} / \mathrm{Ce}^{3+}$ pair. The two case studies demonstrate that detailed kinetics of subtle changes can be uncovered by the combination of in situ X-ray absorption and high energy diffraction methods with PSD.
\end{abstract}

\section{Introduction}

Synchrotron based techniques such as X-ray absorption spectroscopy (XAS), ${ }^{1-3} \mathrm{X}$-ray diffraction (XRD), ${ }^{2,4}$ pair distribution function $(\mathrm{PDF})^{5,6}$ and $\mathrm{X}$-ray scattering ${ }^{7}$ are key tools in catalysis research because they provide access to structural information using relatively easy sample environments and

\footnotetext{
${ }^{a}$ Paul Scherrer Institute, CH-5232 Villigen PSI, Switzerland.

E-mail: davide.ferri@psi.ch; Tel: +41563102781

${ }^{b}$ Empa, Swiss Federal Laboratories for Materials Science and Technology, Laboratory for Solid State Chemistry and Catalysis, Ueberlandstrasse 129, CH-8600 Dübendorf, Switzerland

${ }^{c}$ European Synchrotron Radiation Facility, 6 Rue Jules Horowitz, F-38043 Grenoble, France

${ }^{d}$ Umicore AG\&Co. KG, Rodenbacher Chaussee 4, D-63457 Hanau, Germany $\dagger$ Present address: Condensed Matter Physics Department, University of Zaragoza, 50009 Zaragoza, Spain.
}

under relevant reaction conditions. ${ }^{8,9}$ An important advantage of these methods, over e.g. vibrational spectroscopic techniques, is that relatively thick sample beds can be penetrated using high energy X-rays and therefore information can be obtained at more practically relevant reactor scales. XAS and XRD also probe very different, but complementary, length scales of the catalyst. XAS is element specific and sensitive to short range order and provides structural insight regardless of material crystallinity. XRD is ideally suited to follow structural changes of complex working catalysts because a snapshot of the catalyst can be obtained with simultaneous information on the support material and on supported nanostructures. However, it is only sensitive to long range order and is intrinsically limited to detection of particles larger than $2-3 \mathrm{~nm}$ even with a synchrotron source ${ }^{10}$ As a result of the different length scales probed in the corresponding measurements, the information obtained from XAS and XRD in independent experiments is 
increasingly combined to obtain a global picture of the structure of the catalyst at the very moment it is performing the catalytic event. $^{8,11}$ The two methods can be combined in the same reactor cell or are even coupled (quasi-)simultaneously with the advantage of obtaining structural information at different length scales on the same analysis spot. ${ }^{12,13}$ Finally, the technical progress made in the design of insertion devices, monochromators and detectors now permits sub-second time resolution. However, both techniques are substantially silent, and therefore limited, with respect to surface information as they both mainly probe the bulk structure. Typically, from a spectroscopic viewpoint the signal of the bulk dominates over the possible contribution of the surface thus complicating the interpretation of steady state data acquired in a conventional manner. It is only recently that a method borrowed from infrared spectroscopy, a surface sensitive method, has become increasingly used, which provides the opportunity to access the subtle information on surface reactivity. In order to reveal minute structural changes that are assumed to be associated with surface structural variations, a modulated excitation (ME) approach coupled to phase sensitive detection (PSD) has been shown to improve the $\mathrm{S} / \mathrm{N}$ level by orders of magnitude ${ }^{14,15}$ and to emphasize those components of the system under examination that are changing as a result of an external stimulation. ${ }^{16-18}$ $\mathrm{ME}$ is complementary to steady state analysis of catalysts and facilitates obtaining information on the role of the various evolving species during the experiment. From an experimental viewpoint, ME consists of a repeated stimulation of the catalyst, for example by periodic variation of reactants concentration (concentration ME, cME) while data are collected continuously over the various modulation periods. PSD is then applied to separate the information of components responding to the external stimulus from that of the components that are not responding, e.g. the bulk of the material (if the process is genuinely confined to the surface area of the catalyst), thus potentially providing surface sensitive information. We have previously shown that application of PSD greatly improves the quality of energy dispersive and quick EXAFS data by considering the XANES region. ${ }^{15,19,20}$ Recently, König et al. demonstrated that the methodology can also provide quantitative EXAFS data with an enormous improvement of sensitivity. ${ }^{21}$ Van Beek et $a .^{22}$ showed that variation of the X-ray energy can function as the external stimulus for the experiment and this can provide unprecedented insight into structural dynamics by XRD.

Here, we briefly report two case studies using energy dispersive XAS to explore hydrothermal aging effects on the structure and reactivity of $\mathrm{Rh} / \mathrm{Al}_{2} \mathrm{O}_{3}$ and high energy XRD to monitor the structural changes induced by chemical treatment of a model three-way catalyst, $\mathrm{Pd} / \mathrm{Al}_{2} \mathrm{O}_{3}-\mathrm{Ce}_{1-x} \mathrm{Zr}_{x} \mathrm{O}_{2}$. The two case studies should demonstrate the vast amount of information and the enhanced sensitivity that can be achieved by application of phase sensitive detection coupled with the two X-ray based methods.

\section{Experimental}

The fresh $2 \mathrm{wt} \% \mathrm{Rh} / \mathrm{Al}_{2} \mathrm{O}_{3}$ and $1.6 \mathrm{wt} \% \mathrm{Pd} / \mathrm{Al}_{2} \mathrm{O}_{3}-\mathrm{Ce}_{1-x} \mathrm{Zr}_{x} \mathrm{O}_{2}$ (hereafter, $\mathrm{Pd} / \mathrm{ACZ}$ ) catalysts (70-90 $\mu \mathrm{m}$ sieve fraction) were
Table 1 BET surface area and Rh dispersion values of fresh and aged $\mathrm{Rh} / \mathrm{Al}_{2} \mathrm{O}_{3}$ catalysts

\begin{tabular}{lccc}
\hline Sample & $\mathrm{SSA}^{a}\left(\mathrm{~m}^{2} \mathrm{~g}^{-1}\right)$ & $D^{b}(\%)$ & $d^{b}(\mathrm{~nm})$ \\
\hline Fresh & 134 & 26.3 & 4.2 \\
Aged $973 \mathrm{~K}$ & 103 & 14.8 & 7.4 \\
Aged $1273 \mathrm{~K}$ & 68 & 0.7 & 154.5 \\
${ }^{a}$ Obtained from BET & & & \\
\hline
\end{tabular}

kindly provided by Umicore. Hydrothermal aging of $\mathrm{Rh} / \mathrm{Al}_{2} \mathrm{O}_{3}$ was performed by exposure of the fresh sample to $10 \mathrm{vol} \%$ $\mathrm{H}_{2} \mathrm{O}-10$ vol\% $\mathrm{O}_{2}$-bal. $\mathrm{N}_{2}$ at $973 \mathrm{~K}$ and $1273 \mathrm{~K}$ for $16 \mathrm{~h}$. The fresh $\mathrm{Pd} / \mathrm{ACZ}$ was impregnated with a solution of $\left(\mathrm{NH}_{4}\right)_{3} \mathrm{PO}_{4}$ (resulting in $7.5 \mathrm{wt} \%$ phosphorous) and calcined at $973 \mathrm{~K}$ for $5 \mathrm{~h}$ in air. ${ }^{23}$ Similarly, fresh Pd/ACZ was also thermally aged in air at $973 \mathrm{~K}$ for comparison. The specific surface area (SSA) of the catalysts was determined using a BELmax 00030 instrument. Materials were outgassed in a vacuum at $150{ }^{\circ} \mathrm{C}$ for $1 \mathrm{~h}$ prior to the measurement. The total surface area of the samples was determined by the BET method (Table 1). Rh dispersion was obtained from pulse CO chemisorption using a Micromeritics AutoChem instrument. Prior to the measurements, all samples were dried overnight at $403 \mathrm{~K}$ and reduced under hydrogen at $473 \mathrm{~K}$. Dispersion was determined by assuming a $\mathrm{Rh} / \mathrm{CO}$ stoichiometry of 1. High angular annular dark-field images in scanning mode (HAADF-STEM) were taken by a JEOL FS2200-FEG at $200 \mathrm{kV}$ and in column omega filter. The sample was dispersed in doubledeionized water and dropped on carbon-film-coated copper grids and dried in air.

Time-resolved energy dispersive EXAFS data were measured at the Rh K-edge $\left(E_{0}=23.22 \mathrm{keV}\right)$ at beamline ID24 of ESRF (Grenoble, France) using a $\mathrm{Si}(311)$ polychromator crystal in Bragg configuration and FReLoN CCD camera as described earlier. ${ }^{15}$ The X-ray beam was vertically defocused (to $c a .300 \mu \mathrm{m}$ at the detector). Fresh and aged (under identical conditions) $2 \mathrm{wt} \% \mathrm{Pd} / \mathrm{Al}_{2} \mathrm{O}_{3}$ (Umicore) was mounted at the same focal length as the sample but outside the sample environment and served as the reference to account for the scattering of the polychromatic beam by the majority material in the sample (i.e. the support). ${ }^{24}$ During a full modulation period, 504 spectra (0.26 s time resolution, $0.1 \mathrm{~s}$ actual exposure) were collected..$^{15}$ Here, we will restrict our discussion to the XANES region of the spectra.

Time-resolved high energy XRD data were measured at beamline ID15B of ESRF (Grenoble, France). XRD measurements $\left(86.8 \mathrm{keV}, \lambda=0.143 \AA\right.$, $\left.\Delta E / E \sim 1.4 \times 10^{-3}\right)$ were collected with a digital flat $2 \mathrm{D}$ panel detector (Pixium 4700) at $900 \mathrm{~mm}$ from the sample position. During a full modulation period, 100 high energy XRD patterns ( $0.5 \mathrm{~ms}$ time resolution) were collected.

Both in ED-EXAFS and XRD, the sample bed provided an $\mathrm{X}$-ray transmission path length through the sample of $5 \mathrm{~mm}$. Details of the experimental setup and protocol have been provided earlier. ${ }^{2,15,25}$ Three pneumatic four-port switch valves enable a rapid switch of feedstock composition to the cell. The exhaust of the cell was connected to a mass spectrometer (Omnistar, Pfeiffer) for online detection of reactants and products. 
The following $\mathrm{m} / \mathrm{z}$ signals were monitored online: 4 (He), $18\left(\mathrm{H}_{2} \mathrm{O}\right), 22\left(\mathrm{CO}_{2}\right), 28\left(\mathrm{CO}\right.$ and $\left.\mathrm{N}_{2}\right), 30(\mathrm{NO}), 32\left(\mathrm{O}_{2}\right)$ and $44\left(\mathrm{CO}_{2}\right.$ and $\mathrm{N}_{2} \mathrm{O}$ ). The delay between the trigger signal of the valves located before the cell and the response of the MS placed after the cell to changes of gas phase composition was $c a .6 \mathrm{~s}$.

A full concentration modulation period $(T)$ is defined as the time required to conclude a $5 \mathrm{vol} \% \mathrm{NO} / \mathrm{He} v s$. $5 \mathrm{vol} \% \mathrm{CO} / \mathrm{He}$ $(T=132 \mathrm{~s})$ or $1 \mathrm{vol} \% \mathrm{CO} / \mathrm{He} v s .1 \mathrm{vol} \% \mathrm{O}_{2} / \mathrm{He}(T=50 \mathrm{~s})$ sequence for Rh- and Pd-based samples, respectively. The two gases are admitted to the cell consecutively for an equal time at a flow rate of $80 \mathrm{ml} \mathrm{min}{ }^{-1}$ at $300{ }^{\circ} \mathrm{C}$. In the case of $\mathrm{Rh} / \mathrm{Al}_{2} \mathrm{O}_{3}$, the modulation experiment was started after reduction in flowing 5 vol\% $\mathrm{H}_{2} / \mathrm{He}$ at $573 \mathrm{~K}$ for $30 \mathrm{~min}$. In the case of Pd-based catalysts, identical modulation experiments were performed at room temperature and at $473 \mathrm{~K}$ prior to the concentration modulation experiment at $573 \mathrm{~K}$. The samples were heated at the given temperature in 1 vol\% $\mathrm{O}_{2} / \mathrm{He}$. Then the flow was switched to He until the MS signals were stable and the modulation experiment was started.

The full sets of time-resolved data can be processed into sets of phase-resolved data by the phase sensitive detection procedure (PSD, hereafter demodulation): ${ }^{14}$

$$
A_{k}^{\phi^{\mathrm{PSD}}}(x)=\frac{2}{T} \int_{0}^{T} A(x, t) \sin \left(k \omega t+\phi_{k}^{\mathrm{PSD}}\right) \mathrm{d} t
$$

where $k$ is the demodulation frequency $(k=1$, the fundamental frequency), $\omega$ the stimulation frequency, $\phi^{\mathrm{PSD}}$ the demodulation phase angle and $T$ the modulation period. $A(x, t)$ is the intensity recorded as a function of energy (for XAS) or reciprocal lattice vector $(Q=4 \pi \sin (\theta / 2) / \lambda, \theta$ being the scattering angle and $\lambda$ the wavelength of the incident radiation) and time. The result of PSD is that the components that do not respond to the external stimulation (here, the gas concentration fluctuations) and those that exhibit different frequency responses are absent in these data sets. Therefore, the phase-resolved data are simplified with respect to envelope complexity and greatly with respect to noise. Only data demodulated at the fundamental frequency $(k=1)$ are reported here. For data evaluation, it was considered that the system reached equilibrium within the initial 5 periods, which were not included in the demodulation algorithm. This was confirmed by the MS data. Matlab was used to obtain PSD data; the Simpson series was implemented to calculate the integral of eqn (1). Where required, XAS spectra were background subtracted and normalized using the WinXAS software. $^{26}$

Three-way catalytic activity data were collected using a quartz tubular reactor $\left(d_{\mathrm{i}}=7 \mathrm{~mm}\right)$ loaded with a mechanical mixture of the catalyst sample $(70 \mathrm{mg}$, sieve fraction $300-500 \mu \mathrm{m})$ and SiC (200 mg) firmly packed between two plugs of quartz wool. The reactor was positioned horizontally in a programmable tube furnace. Prior to the light off tests, the catalysts were pre-treated in $\mathrm{N}_{2}$ at $773 \mathrm{~K}$ for $5 \mathrm{~min}$. Then, the catalyst was heated from $348 \mathrm{~K}$ to $773 \mathrm{~K}$ at $1 \mathrm{~K} \mathrm{~min}^{-1}$ in $1000 \mathrm{ppm} \mathrm{CO}$, 150 ppm $\mathrm{C}_{3} \mathrm{H}_{6}, 500$ ppm $\mathrm{NO}_{x}$ and $825 \mathrm{O}_{2}$ (bal. $\mathrm{N}_{2}$ ), corresponding to stoichiometric conditions, at GHSV $=200000 \mathrm{~h}^{-1}$.
Products were analysed at the reactor outlet using a FTIR spectrometer (Nicolet Antaris IGS, ThermoFisher Scientific).

\section{Results and discussion}

\section{$\mathrm{Rh} / \mathrm{Al}_{2} \mathrm{O}_{3}$ : energy dispersive $\mathrm{X}$-ray absorption spectroscopy}

In the first example, we consider $\mathrm{Rh} / \mathrm{Al}_{2} \mathrm{O}_{3}$ as a model three-way catalyst (TWC) used to clean the exhaust gases of stoichiometric engines of passenger vehicles. ${ }^{27}$ Rhodium is essential in the NO reduction by $\mathrm{CO}$ which is considered to be a key reaction in TWC technology. ${ }^{28,29} \mathrm{Al}_{2} \mathrm{O}_{3}$ is sensitive to high temperature conditions that are encountered during engine operation and the associated well-known phase transformations promote the loss of precious metal surface area by particle sintering. In the case of Rh, exposure to high temperatures causes loss of active metal phase by diffusion of $\mathrm{Rh}$ into the $\mathrm{Al}_{2} \mathrm{O}_{3}$ support and supposedly formation of $\mathrm{Rh}$ aluminate species. ${ }^{30-32}$ At this point $\mathrm{Rh}$ is hardly recoverable to the original state. The phenomenon is clearly present in our $\mathrm{Rh} / \mathrm{Al}_{2} \mathrm{O}_{3}$ catalysts. Whereas chemisorption data indicate very low dispersion for the catalyst aged at $1273 \mathrm{~K}$, suggesting the presence of large Rh particles (Table 1), scanning transmission electron micrographs (STEM) confirm the disappearance of the $\mathrm{Rh}$ nano-particles observed in the fresh catalyst (Fig. 1), only EDX analysis demonstrates the presence of $\mathrm{Rh}$. Therefore, Rh re-disperses and diffuses through the $\mathrm{Al}_{2} \mathrm{O}_{3}$ support after exposure to the high

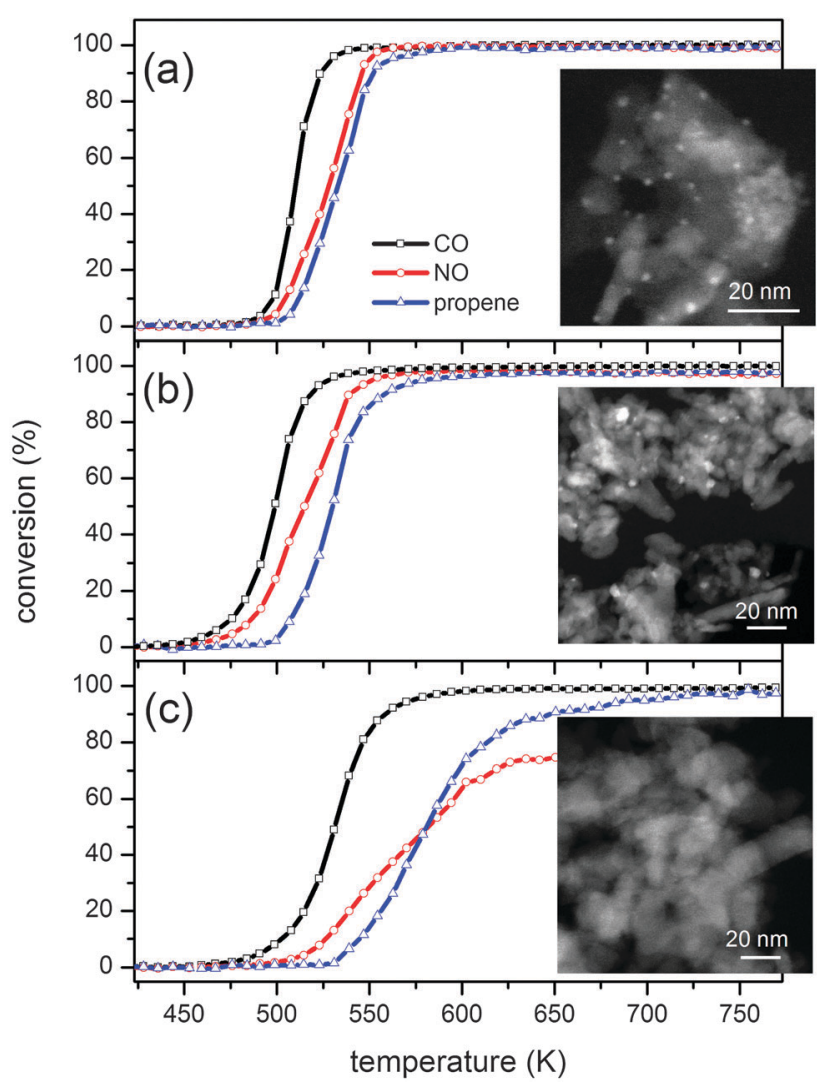

Fig. 1 Three-way catalytic activity and HAADF-STEM images of $2 \mathrm{wt} \% \mathrm{Rh} / \mathrm{Al}_{2} \mathrm{O}_{3}$ (a) fresh, (b) aged at $973 \mathrm{~K}$ and (c) aged at $1273 \mathrm{~K}$. 
temperature hydrothermal conditions. Additionally, the catalysts exhibit decreasing surface area with increasing aging temperature that is associated with $\mathrm{Al}_{2} \mathrm{O}_{3}$ phase transitions (Table 1). The absence of any evident Rh particles in the sample aged at $1273 \mathrm{~K}$ contrasts with the still evident catalytic activity under stoichiometric conditions (Fig. 1) that cannot be attributed solely to the activity of $\mathrm{Al}_{2} \mathrm{O}_{3}$. It is evident from the activity data that NO reduction is increasingly more difficult as the aging temperature is increased. Therefore, concentration modulated excitation (cME) spectroscopy was used to follow the dynamics of structural changes of fresh and aged catalysts during periodic and alternate $\mathrm{CO}-\mathrm{NO}$ pulses. The experimental conditions ( $\mathrm{CO}$ and $\mathrm{NO}_{x}$ concentrations, pulse frequency and gas composition) chosen for the modulation experiment are clearly far from the real TWC ones but are ideally suited to probe the structural changes of dispersed nano-sized catalysts at work..$^{33-37}$ The cME experiment consisted of the alternate variation of CO and NO concentrations from 0 to 5 vol\% in the He feed at $573 \mathrm{~K}^{15}$

Since the discussion will focus on the state of $\mathrm{Rh}$ and on the information contained in phase-resolved spectra obtained from time-resolved ED-EXAFS data according to eqn (1), it is useful to consider the boundary states that Rh encounters during reduction and re-oxidation. The XANES spectra of fresh $\mathrm{Rh} / \mathrm{Al}_{2} \mathrm{O}_{3}$ and after in situ reduction in $5 \mathrm{vol} \% \mathrm{H}_{2} / \mathrm{He}$ at $573 \mathrm{~K}$ are shown in Fig. 2. The difference spectrum between the

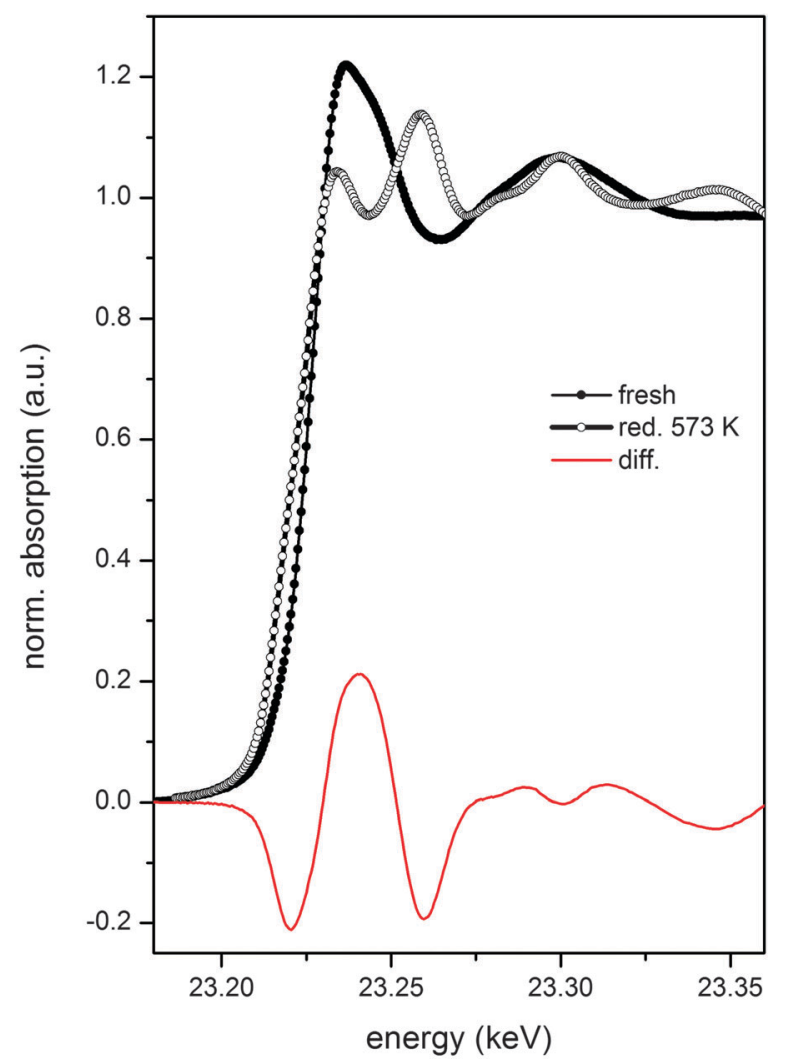

Fig. 2 XANES spectra of $2 \mathrm{wt} \% \mathrm{Rh} / \mathrm{Al}_{2} \mathrm{O}_{3}$, fresh (full symbol) and reduced at $573 \mathrm{~K}$ (open symbol) and of the difference between oxidized and reduced states. oxidized and the metallic states of $\mathrm{Rh} / \mathrm{Al}_{2} \mathrm{O}_{3}$ represents the maximum expected variation of the oxidation state during the red-ox pulses of the cMES study. The difference spectrum should be then featured with varying amplitude in the phaseresolved spectra, if the red-ox pulsing causes Rh to reversibly alternate between reduced and oxidized states. In first approximation, the fraction of $\mathrm{Rh}$ that responds to the red-ox stimulation of a cME experiment can be estimated assuming that the intensity of the signals of the difference spectrum is linear with extent of reduction and oxidation.

Fig. 3a-c shows the XANES region of the averaged timeresolved ED-EXAFS data recorded at the Rh K-edge at $573 \mathrm{~K}$ over the modulation period for fresh and hydrothermally aged catalysts. The data for the fresh catalyst have been already described in detail elsewhere ${ }^{15}$ and are reported here as a starting point for comparison with the data obtained for aged catalysts. The spectra show the three catalysts exhibit a different average oxidation state of Rh. Because the samples were reduced in situ at $573 \mathrm{~K}$ prior to the modulation experiment, the fresh sample (Fig. 3a) and the one aged at $973 \mathrm{~K}$ (Fig. 3b) exhibit mainly variations of the oxidation state around the reduced state. The fraction of reduced $\mathrm{Rh}$ at $573 \mathrm{~K}$ clearly decreases with increasing aging temperature and the time-resolved spectra of the catalyst aged at $1273 \mathrm{~K}$ show a persistent oxidized Rh state and no evidence of reduced Rh (Fig. 3c). ${ }^{38}$ The increasing fraction of oxidized $\mathrm{Rh}$ is typically understood as the result of diffusion of $\mathrm{Rh}$ into the $\mathrm{Al}_{2} \mathrm{O}_{3}$ support with the consequent loss of active phase and formation of irreducible $\mathrm{Rh} .{ }^{32}$ This process seems to be already effective after aging at $973 \mathrm{~K}$, though $\mathrm{Rh}$ nano-particles are still present (Fig. 1). Fig. 3 also shows that only minor changes are observed around the whiteline of fresh $\mathrm{Rh} / \mathrm{Al}_{2} \mathrm{O}_{3}$ and of the catalyst aged at $973 \mathrm{~K}$. In the case of the catalyst aged at $1273 \mathrm{~K}$, there is no obvious indication of any spectral change apparently suggesting that the catalyst is not responding to the $\mathrm{CO}-\mathrm{NO}$ modulation.

The corresponding phase-resolved spectra of Fig. 3d-f are able to capture subtle changes of the time-resolved spectra with high signal-to-noise ratio. ${ }^{15}$ Beside minor intensity differences, the phase-resolved spectra of fresh and aged at $973 \mathrm{~K} \mathrm{Rh} / \mathrm{Al}_{2} \mathrm{O}_{3}$ are rather similar. Small variations of the spectra of the sample aged at $973 \mathrm{~K}$ occur above $23.27 \mathrm{keV}$. The spectra obtained at $573 \mathrm{~K}$ match well the difference spectrum obtained from the two boundary states of $\mathrm{Rh} / \mathrm{Al}_{2} \mathrm{O}_{3}$ presented in Fig. 2. This observation demonstrates that during the $\mathrm{CO}-\mathrm{NO}$ modulation at $573 \mathrm{~K}$ the fresh catalyst undergoes periodic partial re-oxidation of $\mathrm{Rh}$ compared to the initial reduced state. ${ }^{15}$ In marked contrast, $\mathrm{Rh} / \mathrm{Al}_{2} \mathrm{O}_{3}$ aged at $1273 \mathrm{~K}$ exhibits the least intensity variation, and above $23.27 \mathrm{keV}$ the spectral oscillations are strongly damped. However, it is important to stress that the PSD reveals a fraction of $\mathrm{Rh}$ responding to the external stimulation to the experiment and provides features that in principle can be quantified.

The patterns of the phase-resolved spectra are associated with the change between reduced and oxidized states. As discussed, the Rh oxidation state of the fresh catalyst periodically increases and decreases. The average oxidation state is 

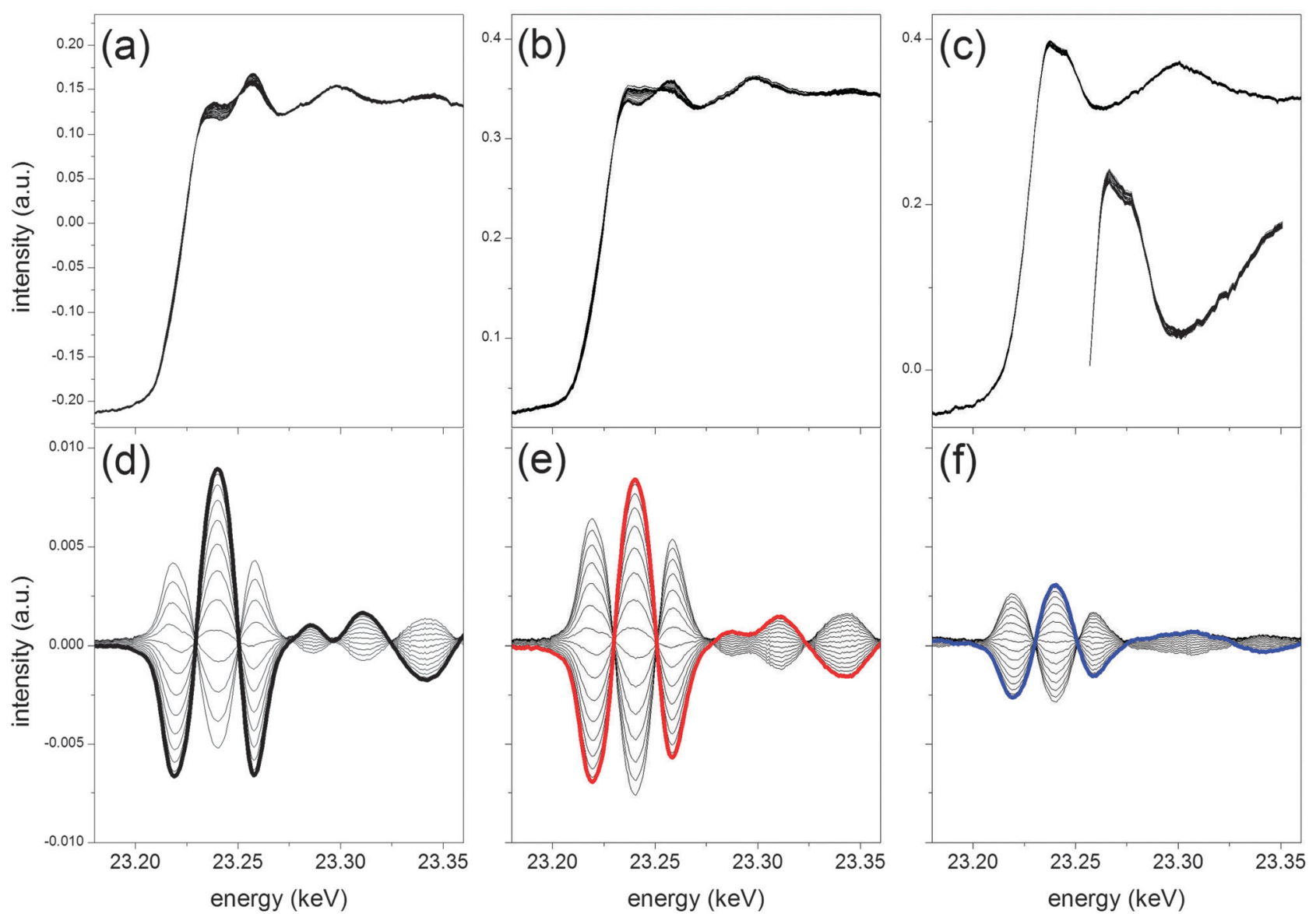

Fig. 3 XANES region of the average time-resolved ED-EXAFS spectra at the Rh K-edge during a CO/NO modulation experiment ( $T=132 \mathrm{~s})$ at $573 \mathrm{~K}$ over fresh $2 \mathrm{wt} \%$ $\mathrm{Rh} / \mathrm{Al}_{2} \mathrm{O}_{3}(\mathrm{a})$, aged at $973 \mathrm{~K}(\mathrm{~b})$ and aged at $1273 \mathrm{~K}(\mathrm{c})$. The inset in (c) is a magnification of the whiteline region. Corresponding phase-resolved spectra at $\varphi^{\mathrm{PSD}}=0-120^{\circ}(\mathrm{d})$, $0-150{ }^{\circ} \mathrm{C}(\mathrm{e})$ and $0-150^{\circ}$ (f), respectively. The bold spectra are drawn to guide the eye.

close to the metallic state as can be seen from the time-resolved spectra of Fig. 3. Semi-quantitative estimation of the amount of $\mathrm{Rh}$ that is reversibly responding to the $\mathrm{CO}-\mathrm{NO}$ pulses from the comparison of the spectra of Fig. 3 with the reference states of Fig. 2 indicates that $c a .6 \%$ of $\mathrm{Rh}$ is involved in the changes observed at $573 \mathrm{~K}$. In the case of $\mathrm{Rh} / \mathrm{Al}_{2} \mathrm{O}_{3}$ aged at $973 \mathrm{~K}$, changes occur to a similar extent. However, since the oxidation state of $\mathrm{Rh}$ is on average higher than that in the fresh catalyst, this $\mathrm{Rh}$ component is a fraction of the $\mathrm{Rh}$ effectively exposed at the $\mathrm{Al}_{2} \mathrm{O}_{3}$ surface. The catalyst aged at $1273 \mathrm{~K}$ remains oxidized during the experiment. Only $c a .2 \%$ of the total $\mathrm{Rh}$ responds to the CO-NO modulation and this fraction can be detected only by PSD. Hence, hydrothermal aging effectively caused a substantial change of $\mathrm{Rh}$ dispersion with possible effects on activity and selectivity. ${ }^{39-41}$

Once the set of phase-resolved spectra is obtained by PSD, it becomes easier to adequately select signals from the timeresolved spectra and to display their kinetics during the full modulation period. This is shown in Fig. 4 for the whiteline signal ( $c a .23 .24 \mathrm{keV}$ ) of the three catalysts. An increase of amplitude of the signal at $23.24 \mathrm{keV}$ corresponds to an increase of the oxidic character (oxidation), whereas a decrease corresponds to increased metallic character. It is evident that reduction by $\mathrm{CO}$ of partially oxidized $\mathrm{Rh}$ formed in the NO half-period is faster than its re-oxidation by NO. Consumption of partially oxidized Rh species occurs within $6 \mathrm{~s}$ upon admittance of $\mathrm{CO}$ and does not proceed further till the conclusion of the pulse. Concurrent with the switch, the mass spectrometric data (Fig. 4) show a sharp maximum of production of species with $\mathrm{m} / \mathrm{z} 44\left(\mathrm{CO}_{2}\right.$ and $\left.\mathrm{N}_{2} \mathrm{O}\right)$ that is clearly related to $\mathrm{Rh}$ reduction and $\mathrm{CO}$ oxidation $\left(\mathrm{Rh}-\mathrm{O}+\mathrm{CO} \rightarrow \mathrm{Rh}+\mathrm{CO}_{2}\right)$. However, the reactivity of undissociated NO species adsorbed in the NO pulse further contributes to the MS signal and explains the additional formation of $\mathrm{N}_{2} \mathrm{O}$ for the three catalysts visible in the inset of Fig. 4. The oxidation state of Rh changes again at the $\mathrm{CO} \rightarrow \mathrm{NO}$ switch. The onset of re-oxidation of $\mathrm{Rh}$ is delayed with respect to the switch by a time that decreases from $c a .13 \mathrm{~s}$ for fresh $\mathrm{Rh} / \mathrm{Al}_{2} \mathrm{O}_{3}$ to $9 \mathrm{~s}$ and $7 \mathrm{~s}$ for the catalysts aged at 973 and $1273 \mathrm{~K}$, respectively. These values are truly associated with the oxidation process because they are larger than the time required to achieve reduction in the $\mathrm{CO}$ pulse and the time needed to observe changes in the MS after the valve switch. The change of intensity of the whiteline signal of fresh $\mathrm{Rh} / \mathrm{Al}_{2} \mathrm{O}_{3}$ can be fitted well by an exponential function in agreement with re-oxidation being dictated by NO dissociation. Only the synchronously measured infrared data were able to show that the 


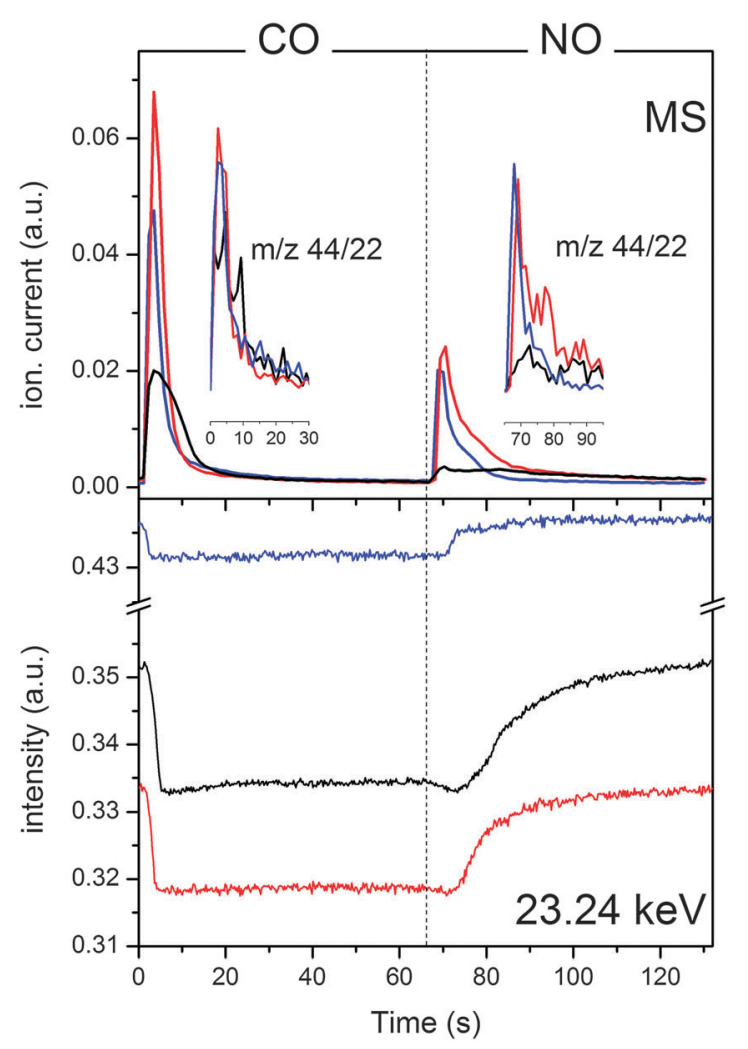

Fig. 4 Top panel: temporal response of the MS signal corresponding to $\mathrm{m} / \mathrm{z}=$ $44\left(\mathrm{CO}_{2}\right)$ during a $\mathrm{CO} / \mathrm{NO}$ modulation experiment $(T=132 \mathrm{~s})$ at $573 \mathrm{~K}$ on $2 \mathrm{wt} \%$ $\mathrm{Rh} / \mathrm{Al}_{2} \mathrm{O}_{3}$ : fresh (black), aged at $973 \mathrm{~K}$ (red) and aged at $1273 \mathrm{~K}$ (blue). The insets show the ratio between $\mathrm{m} / \mathrm{z} 44$ and 22 . Bottom panel: temporal response of the whiteline signal $(23.24 \mathrm{keV})$ from the time-resolved spectra of the same experiment. The signal has been selected from the phase-resolved spectra of Fig. 3.

process occurs stepwise through formation of $\mathrm{Rh}^{0}-\mathrm{NO}$, $\mathrm{Rh}-\mathrm{NO}^{-}$and $\mathrm{Rh}-\mathrm{NO}^{+}$species. ${ }^{15,42}$ Fitting of the temporal profiles becomes increasingly difficult with increasing aging temperature. In the catalyst aged at $1273 \mathrm{~K}$, the signal at $23.24 \mathrm{keV}$ clearly gains intensity at least in two stages, first fast and then slower, a process that can be tentatively associated with an alternative oxidation mechanism involving different adsorbed NO species. Within the time required to set re-oxidation, species with $m / z 44$ experience again a maximum with the exception of fresh $\mathrm{Rh} / \mathrm{Al}_{2} \mathrm{O}_{3} . \mathrm{N}_{2} \mathrm{O}$ is also produced at a similar rate and in strong contrast to the NO $\rightarrow$ CO switch. The fresh catalyst exhibits only a very small $\mathrm{m} / \mathrm{z} 44$ signal and is therefore poorly active at the $\mathrm{CO} \rightarrow$ NO switch. The aged catalysts are active but not selective. Therefore, in general, the change from reduced to partially oxidized $\mathrm{Rh}$ is not favorable to the reaction on particles of $c a .3 \mathrm{~nm}$ in diameter. ${ }^{15}$ In contrast, Fig. 4 reveals that activity is systematically higher at the NO $\rightarrow$ CO switch, i.e. when the oxidation state changes abruptly from partially oxidized to reduced. Fig. 4 also shows that hydrothermal aging causes differences in the kinetics of reduction and re-oxidation. In the presence of $\mathrm{CO}$, the major difference between the catalysts is the extent of reduction that correlates with the mentioned average oxidation state observed in the timeresolved spectra. The higher the aging temperature, the lower the amount of $\mathrm{Rh}$ that is sensitive to the CO-NO modulation and the faster the reduction. The initial apparent reduction rate increased from -0.0017 a.u. $\mathrm{s}^{-1}$ for the fresh catalyst and the sample aged at $973 \mathrm{~K}$ to -0.00096 a.u. $\mathrm{s}^{-1}$ for the sample aged at $1273 \mathrm{~K}$. However, it is especially in the oxidation sequence that structural changes become effective. The oxidation takes place faster with increasing aging temperature and with increasing $\mathrm{Rh}$ diffusion into the $\mathrm{Al}_{2} \mathrm{O}_{3}$. Therefore, the less $\mathrm{Rh}$ is exposed at the $\mathrm{Al}_{2} \mathrm{O}_{3}$ surface the faster the re-oxidation occurs. Oxidation by NO is concluded $c a$. $10 \mathrm{~s}$ after introducing NO to the catalyst aged at $1273 \mathrm{~K}$.

Comparison of the three catalysts based on their activity is complicated by the different size and loading of the Rh entities involved in the catalytic process, the difference being caused by the hydrothermal aging. Despite the lower amount of Rh still available at the $\mathrm{Al}_{2} \mathrm{O}_{3}$ surface and the average oxidation and coordination state of Rh, activity of the catalyst aged at $1273 \mathrm{~K}$ in terms of MS signal is maintained at comparable levels to that of the fresh catalyst (Fig. 4). Since activity is higher when the state of $\mathrm{Rh}$ converts from partially oxidized to reduced (the $\mathrm{NO} \rightarrow \mathrm{CO}$ switch) and concomitantly the aged catalysts also display low selectivity to $\mathrm{N}_{2}$ (major contribution of $\mathrm{N}_{2} \mathrm{O}$ to $\mathrm{MS}$ signal $m / z 44$ ), the oxidation by NO produces oxidized Rh species in the aged catalysts that are prone to produce $\mathrm{N}_{2} \mathrm{O} .^{41}$ These species are likely not associated with well-defined $\mathrm{Rh}$ particles since the two aged catalysts behave very similarly despite the threefold contribution of $\mathrm{Rh}$ to the red-ox process in the catalyst aged at $973 \mathrm{~K}$. In contrast, the data for the fresh catalyst indicate that a (thin) layer of $\mathrm{RhO}_{x}$ on reduced particles may be effectively the active site environment required for both activity and selectivity. Since the NO $\rightarrow$ CO switch in this work also includes a $\mathrm{CO}$ oxidation step, wherein the Rh surface is covered by $\mathrm{O}$ and $\mathrm{N}$ atoms as a result of $\mathrm{NO}$ dissociation, the data are in agreement with the reported CO oxidation dependence on the Rh oxidation state. ${ }^{43-45}$ The size range of the Rh particles of fresh $\mathrm{Rh} / \mathrm{Al}_{2} \mathrm{O}_{3}$ and the temperature at which the modulation experiment is performed make us confident that $\mathrm{Rh}$ particle disruption did not intervene, which was confirmed by the reversibility of the observed changes. This may not be correct for the catalyst aged at $1273 \mathrm{~K}$ given the susceptibility of small Rh clusters to re-dispersion. ${ }^{39,46}$

Finally, it is important to note that the experiments show that in the specific case of this $\mathrm{Rh} / \mathrm{Al}_{2} \mathrm{O}_{3}$ example ME confers surface sensitivity to X-ray absorption spectroscopy. Given the fact that the fresh catalyst is composed of well-defined $\mathrm{Rh}$ particles and that the average oxidation state is close to the metallic state during experiment, the periodic reduction-oxidation that is captured by PSD needs to be associated with the surface re-oxidation of the particles. ${ }^{15}$ In the case of the catalyst aged at $1273 \mathrm{~K}, \mathrm{Rh}$ is mainly re-dispersed within $\mathrm{Al}_{2} \mathrm{O}_{3}$ and thus difficult to reduce at $573 \mathrm{~K}$. PSD is able to reveal that small fraction of $\mathrm{Rh}$ still available for reaction on the surface of the support. This Rh cannot be captured solely by examining the time-resolved data in a conventional manner. Spectral changes associated with the red-ox pulsing above the whiteline are especially difficult to be detected by eye. PSD also greatly 
enhances sensitivity in the region where structural information lies that cannot be obtained by conventional difference spectroscopy. ${ }^{15,21}$ We are currently elaborating a protocol for the conventional EXAFS analysis of these spectra that is alternative to the one proposed recently. ${ }^{21}$

\section{$\mathrm{Pd} / \mathrm{Al}_{2} \mathrm{O}_{3}-\mathrm{Ce}_{1-x} \mathrm{Zr}_{x} \mathrm{O}_{2}$ : high energy $\mathrm{X}$-ray diffraction}

A major cause for TWC aging is the deposition of chemical elements originating from oil and fuel additives, which predominantly localize at the entrance of the automotive catalytic converter. ${ }^{47}$ Phosphorus (P) can react with both $\mathrm{Al}_{2} \mathrm{O}_{3}$ and $\mathrm{CeO}_{2}$ components to form stable $\mathrm{AlPO}_{4}$ and $\mathrm{CePO}_{4}$, thereby severely diminishing the efficiency of the TWC. This is typically associated with the locking of the $\mathrm{Ce}^{4+} / \mathrm{Ce}^{3+}$ red-ox pair, which is responsible for the oxygen exchange properties of the TWC. ${ }^{48,49}$ Precious metal nano-particles, and therefore the whole associated chemistry, are also affected by the presence of $\mathrm{P}^{50}$ Hence, the second case study presents data from another experiment carried out within the same sample environment, in which $1.6 \mathrm{wt} \% \mathrm{Pd} / \mathrm{ACZ}$ is subjected to short (25 s) alternate switches of diluted $\mathrm{CO}$ and $\mathrm{O}_{2}$ flows at $573 \mathrm{~K}$ while high energy $\mathrm{XRD}$ data are acquired at high time resolution ( $0.5 \mathrm{~s}$ per pattern). The aging issue is faced in this case by either thermal or chemical treatment with phosphorous as the chemical poison using a procedure reported earlier. ${ }^{23}$ The decreasing BET surface area from $119 \mathrm{~m}^{2} \mathrm{~g}^{-1}$ for the fresh catalyst to $96 \mathrm{~m}^{2} \mathrm{~g}^{-1}$ after thermal treatment and to $50 \mathrm{~m}^{2} \mathrm{~g}^{-1}$ for the $\mathrm{P}$ aged one demonstrates that $\mathrm{P}$ induces clogging of the metal oxide supports in agreement with similar observations on $\mathrm{Pd} / \mathrm{Al}_{2} \mathrm{O}_{3}{ }^{23}$ The presence of $\mathrm{P}$ induces a shift of the methane oxidation activity of $\mathrm{Pd} / \mathrm{Al}_{2} \mathrm{O}_{3}$ under stoichiometric conditions to higher temperatures that is more severe than the effect of thermal aging. ${ }^{23}$

For the sake of brevity we discuss here the diffraction data obtained at $573 \mathrm{~K}$; however, the samples underwent the same experiment at $473 \mathrm{~K}$ followed by a temperature ramp in $5 \mathrm{vol} \%$ $\mathrm{O}_{2} / \mathrm{He}$. Fig. 5 displays the two dimensional representation of the modulation XRD experiments on the three catalysts. The colour maps of fresh and thermally aged Pd/ACZ clearly show that the catalysts undergo similar structural changes to previous reports. ${ }^{51}$ This is visible from the periodic variation of the $d$ spacing of some reflections and from the periodic appearance of other reflections (e.g. at ca. $2.8 \AA^{-1}$ ). In the case of the $\mathrm{P}$ poisoned catalyst, it is clear that the dynamic changes are massively damped, which is attributed to the presence of $\mathrm{P}$.

Fig. 6a shows the time-resolved high energy XRD data obtained from the fresh Pd/ACZ. The patterns are dominated by the reflections of cubic $\mathrm{CZ}$ and of $\gamma-\mathrm{Al}_{2} \mathrm{O}_{3}$; precious little information is obtained on the presence of $\mathrm{Pd}$ phases. Upon inspection by eye, the time-resolved data exhibit a change in the $d$ of the CZ reflections and at ca. $2.8 \AA^{-1}$ that are visible in Fig. 5 . The measurable and reversible variation of the lattice parameter associated with the $\mathrm{CZ}$ reflections is $0.024 \AA$ corresponding to $c a$. $0.49 \%$ expansion of the $\mathrm{CeO}_{2}$ lattice upon reduction by $\mathrm{CO}$ followed by oxidation by $\mathrm{O}_{2}$, and thus a reversible reduction of $\mathrm{Ce}^{4+}$. Detailed kinetics of the system, i.e. of the $\mathrm{CZ}$ phase and the Pd phase, could in principle be extracted from the time-resolved data. ${ }^{51}$ Application of PSD greatly simplifies the data in a complex system as this, since the contribution of alumina can be filtered out likewise the contribution of that major fraction (bulk) of $\mathrm{CZ}$ that is not responding to the $\mathrm{CO}-\mathrm{O}_{2}$ concentration modulation. Therefore, it is only the very subtle variations around the reflections that experience some changes that are highlighted, again with high resolution. Moreover, PSD provides the information that is not accessible from the time-resolved data as shown in Fig. 6. For example, the differential signals around the $\mathrm{CZ}$ reflections mirror the variation of lattice parameter observed in the timeresolved data. However, the intensity change of signals at 2.78 and $3.22 \AA^{-1}$ becomes clearly visible only in the PSD data (Fig. 6). These signals are readily associated with the formation of metallic palladium, ${ }^{52,53}$ thus with reduction of Pd during the CO pulse. Reliable estimation of the Pd crystallite size using the PSD data and the reflection at $2.78 \AA^{-1}$ does not seem possible because of the shape of the signal. The sharp $\operatorname{Pd}(111)$ reflection overlaps with a broader signal indicating a crystallite size
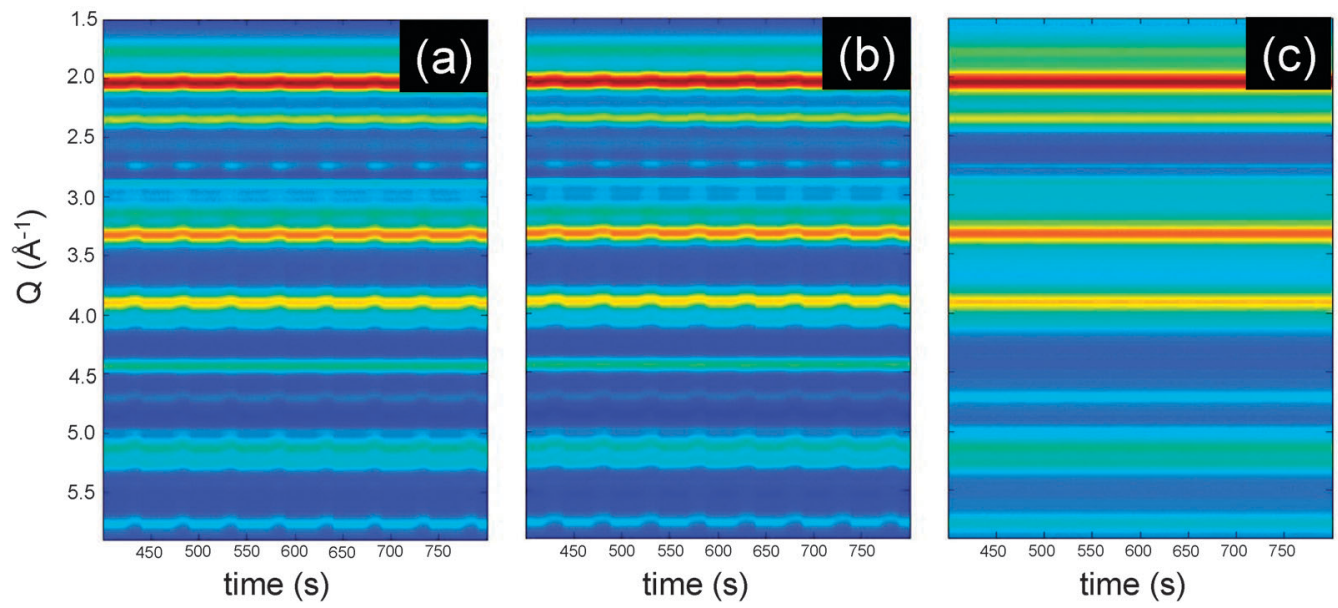

Fig. 5 Colour map representation of (a) fresh, (b) thermally aged and (c) P-treated Pd/ACZ during a $\mathrm{CO} / \mathrm{O}_{2}$ modulation experiment $(T=50 \mathrm{~s})$ at $573 \mathrm{~K}$. 

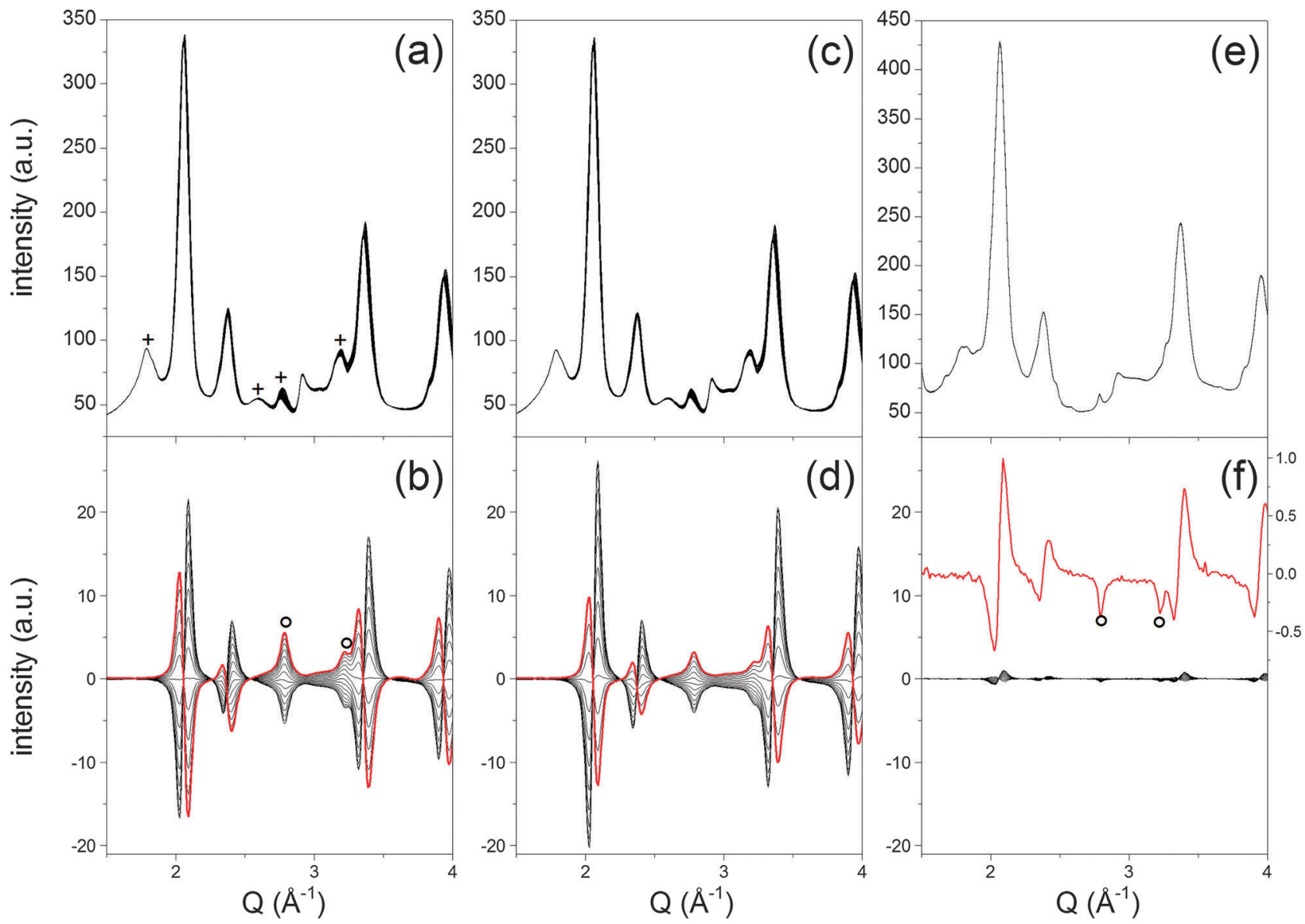

Fig. 6 Time-resolved high energy XRD data of (a) fresh, (c) thermally aged and (e) P-treated Pd/ACZ during a CO/O 2 modulation experiment at $573 \mathrm{~K}$. (b, d and f) Corresponding selected sets of phase-resolved data obtained for $\varphi^{\mathrm{PSD}} 30-180^{\circ}, 50-180^{\circ}$ and $70-180^{\circ}$, respectively. The red trace in $(\mathrm{f})$ is a magnification of $\varphi^{\mathrm{PSD}}=90^{\circ}$. Red traces are intended to guide the eye. $(+)$ Contribution of $\mathrm{Al}_{2} \mathrm{O}_{3}$ reflections; $(\mathrm{O}) \mathrm{Pd}$ reflections.

distribution that using a conventional approach leads to the overestimation of the crystallite size. ${ }^{54}$ The two signals likely originate from the simultaneous response of Pd deposited on $\mathrm{CZ}$ and on alumina, respectively. We associate the broad signal with small Pd entities deposited on CZ, whereas the sharp peak is likely due to larger Pd particles on alumina, without excluding the contribution from small Pd particles present on $\mathrm{Al}_{2} \mathrm{O}_{3}$ to the broad signal. The assignment of the sharp signals at 2.78 and $3.22 \AA^{-1}$ to Pd deposited on alumina can be inferred by the observation that the kinetics of these signals is different from that of the reflections of CZ. Therefore, PSD is highly advantageous to visualize this in a simple way. The set of PSD data of Fig. $6 \mathrm{~b}$ can be analysed in more detail and this is demonstrated in Fig. 7. A pattern $\left(\varphi^{\mathrm{PSD}}=130^{\circ}\right)$ can be isolated from the PSD data in which further reflections associated with metallic Pd are clearly discernible at $2.78,3.21,4.54,5.33$ and $5.57 \AA^{-1}$ (Fig. 7a). The reflections are accompanied by other peaks at 2.36, 3.74, $4.10,4.74$ and $5.80 \AA^{-1}$ that are not clearly visible in the pattern at $\varphi^{\mathrm{PSD}}=180^{\circ}$ (Fig. 7b) because of the overwhelming CZ reflections, and cannot be observed in other PSD patterns. These signals have opposite sign compared to the reflections of metallic $\mathrm{Pd}$. The signals are unambiguously ascribed to the formation of the PdO phase upon re-oxidation. Additionally, the same
$\varphi^{\mathrm{PSD}}=130^{\circ}$ pattern exhibits no signals of CZ clearly suggesting that the dynamic changes involving Pd deposited on alumina follow different kinetics compared to those of CZ reductionoxidation. Therefore, PSD renders the whole PdO-Pd reductionre-oxidation on the alumina component of a complex system visible and distinguishable from the chemistry occurring on CZ.

Based on the above observations for the fresh catalyst, the same experiments performed on the thermally aged and chemically treated catalysts can also be interpreted. The catalyst thermally aged at $973 \mathrm{~K}$ exhibits a very similar behavior to that of the fresh catalyst ( $0.49 \%$ lattice expansion) indicating that thermal aging at this temperature does not, in a qualitative sense, affect the structural-reactive properties of the fresh system. However, this is only the conclusion that can be drawn from the simple comparison of the time-resolved data. Only the kinetics are able to really tell us whether a substantial difference exists. Fig. 8 shows that in the fresh catalyst the expansion of the $\mathrm{CZ}$ lattice as a result of reduction occurs in a relatively narrower time window compared to that on the catalyst aged at $973 \mathrm{~K}$. Similarly, the intensity increase of the Pd reflection at $2.78 \AA^{-1}$, i.e. Pd reduction, also follows the same tendency. Therefore, Pd reduction on the fresh catalyst occurs to a lesser extent, or is retarded compared to the thermally aged catalyst. 


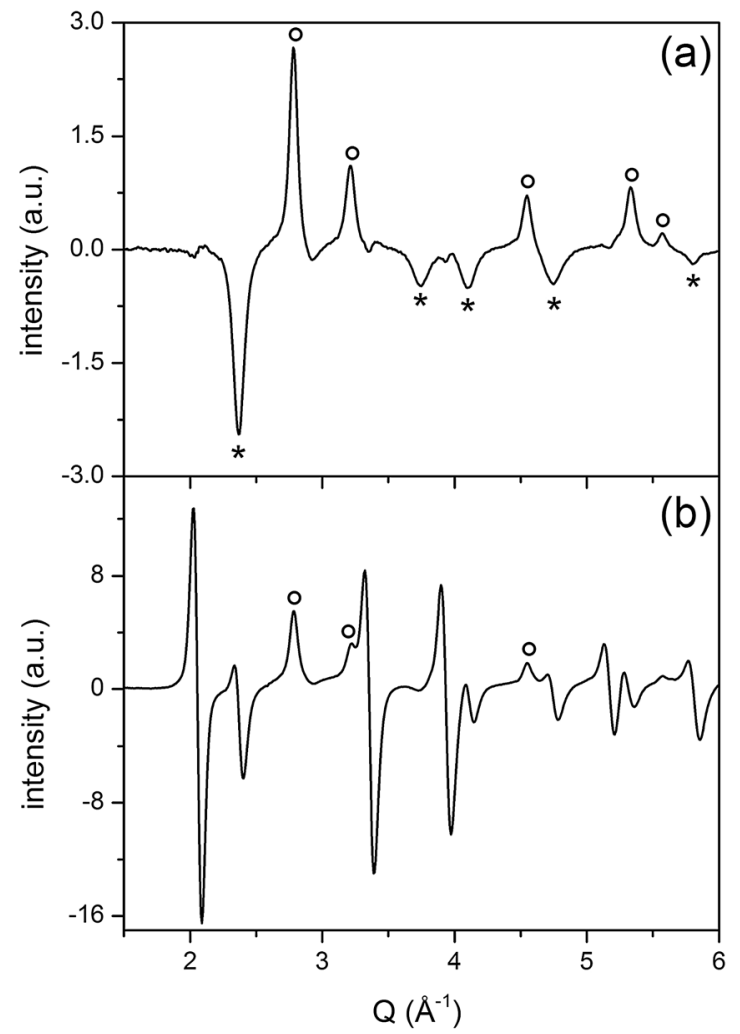

Fig. 7 Selected PSD data at $\varphi^{\mathrm{PSD}} 130^{\circ}$ (a) and $180^{\circ}$ (b) for Pd/ACZ obtained from the $\mathrm{CO} / \mathrm{O}_{2}$ modulation experiment at $573 \mathrm{~K}$ of Fig. 6. (O) Pd reflections; (*) $\mathrm{PdO}$ reflections.

This observation is crucial for the oxygen exchange capability of the catalyst. That the window in which palladium and cerium remain reduced is larger upon thermal treatment indicates that the capability of $\mathrm{CZ}$ to buffer the oxygen deficiency has been reduced because of the thermal treatment. This may be supported by the lower specific surface area of the aged catalyst (Table 1). Furthermore, the behaviour of the $\operatorname{Pd}(111)$ peak is also different compared to that of Ce(111). This is especially visible in the $\mathrm{O}_{2}$ pulse where metallic Pd persists and re-oxidation is slower than that of $\mathrm{Ce}^{3+}$. We associate this behaviour to the fact that, as mentioned before, the selected $\mathrm{Pd}$ peak is the contribution of the Pd deposited on $\mathrm{Al}_{2} \mathrm{O}_{3}$ and on $\mathrm{CZ}$. The response of Pd to the environment during the experiment is different on the two materials because of the nature of the interaction between Pd and the two metal oxides. Pd can profit from the oxygen supply offered by $\mathrm{CZ}$ in the presence of a reducing agent. Therefore, the slow loss of the Pd reflection in the $\mathrm{O}_{2}$ pulse is associated with the fraction of Pd deposited on $\mathrm{Al}_{2} \mathrm{O}_{3}$.

In the case of the $\mathrm{P}$ poisoned catalyst, which was also calcined at $973 \mathrm{~K}$, the time-resolved data do not present similar noticeable changes (Fig. 6e). Also, no specific reflections of $\mathrm{AlPO}_{4}$ and $\mathrm{CePO}_{4}$ can be clearly observed because of the overlap with the reflections of $\mathrm{Al}_{2} \mathrm{O}_{3}$ and $\mathrm{CZ}$, and of the low concentration of these phases. ${ }^{27,48}$ PSD (Fig. 6f) reveals only extremely tiny variations of both the CZ lattice parameter $(0.017 \%)$ and

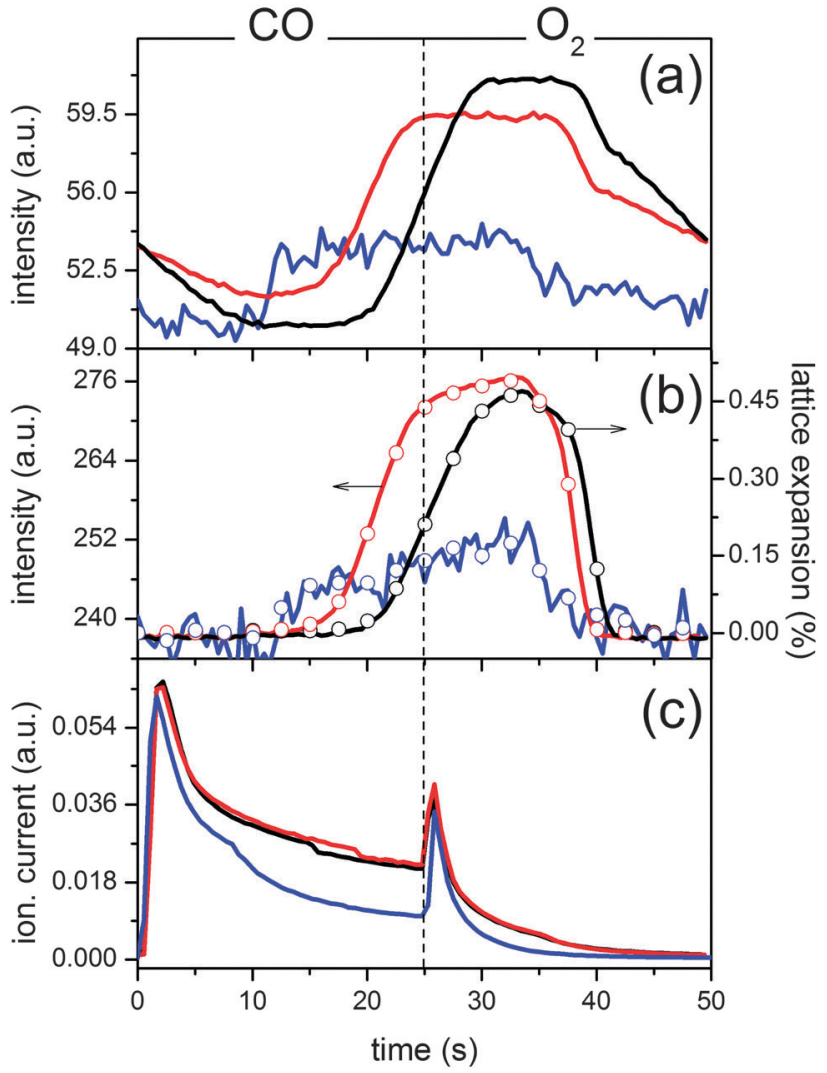

Fig. 8 Temporal behaviour of selected reflections of the data of Fig. 6 obtained for fresh Pd/ACZ (black), thermally aged (red) and P-treated (blue, scaled by factor 5): (a) $\operatorname{Pd}(111)\left(2.78 \AA^{-1}\right)$ and (b) $\operatorname{Ce}(111)\left(2.06 \AA^{-1}\right)$ reflections. Open symbols represent calculated lattice expansion values of selected time-resolved data. (c) Mass spectrometric data $\left(\mathrm{m} / \mathrm{z}=44, \mathrm{CO}_{2}\right)$ for a full modulation period.

the intensity of the Pd peaks, whereas again none of the peaks in the PSD data can be associated with the contribution of $\mathrm{AlPO}_{4}$ and $\mathrm{CePO}_{4}$ phases in agreement with their inert nature under these experimental conditions. Nevertheless, it is clear that a red-ox process is still at work. Though a dynamic process involving $\mathrm{CZ}$ is still visible from the differential but very weak $\mathrm{CZ}$ reflections, if the data of Fig. $6 \mathrm{f}$ are compared with those of Fig. $6 \mathrm{~b}$ the reflections corresponding to Pd are changing to a larger extent compared to those of CZ. This seems to indicate that though the effect of $\mathrm{P}$ extends to the whole catalyst, it affects the CZ more severely, and correspondingly, the fraction of metal deposited on it. Compared to the two other catalysts, the kinetics of the selected signals in Fig. 8 clearly shows that the extent of reduction is far lower for the poisoned catalyst. Additionally, it also provides information on the fact that the fraction of Pd that is still subject to the chemistry of the $\mathrm{CO}-\mathrm{O}_{2}$ modulation, likely part of the Pd deposited on $\mathrm{Al}_{2} \mathrm{O}_{3}$, reduces much earlier as a result of the loss of the red-ox process of the $\mathrm{Ce}^{4+} / \mathrm{Ce}^{3+}$ pair induced by $\mathrm{P}$ thus losing the advantage of the presence of $\mathrm{CZ}$.

These findings are further supported by the synchronous mass spectrometric data (Fig. 8c). The MS profiles corresponding to $\mathrm{CO}_{2}$ evolution $(\mathrm{m} / \mathrm{z}=44)$ are very similar in the three catalysts and are in agreement with literature data. ${ }^{55}$ 
Two peaks at the $\mathrm{O}_{2} \rightarrow$ CO (large) and $\mathrm{CO} \rightarrow \mathrm{O}_{2}$ (small) switches are associated with the oxidation of adsorbed $\mathrm{CO}$ on Pd and re-oxidation of $\mathrm{Ce}^{3+}$, respectively. ${ }^{56,57}$ The $\mathrm{CO}_{2}$ evolution extends after the maximum until the end of the $\mathrm{CO}$ pulse, whereas it quickly vanishes in the $\mathrm{O}_{2}$ pulse. The continuous $\mathrm{CO}_{2}$ evolution in the $\mathrm{CO}$ pulse is associated with the presence of $\mathrm{CZ}$ and its oxygen storage capacity. Since the $\mathrm{CO}_{2}$ maxima at ca. $2 \mathrm{~s}$ are almost identical, the difference between the catalysts is evident predominantly in the time regime $10-25 \mathrm{~s}$, where the P-poisoned catalyst exhibits $c a .50 \%$ less $\mathrm{CO}_{2}$ evolution. This seems to indicate that the effect of aging is explicit under steady state conditions rather than at the switches where the catalysts behave very similarly. Therefore, aging strongly affects the oxygen exchange capacity of the catalyst that is manifested during the $\mathrm{CO}$ pulse. After $10 \mathrm{~s}$ under $\mathrm{CO}, \mathrm{CO}_{2}$ evolution starts decreasing; at the moment when the $\operatorname{Pd}(111)$ reflection likely of $\mathrm{Pd}$ on $\mathrm{Al}_{2} \mathrm{O}_{3}$ becomes measurable in the high energy XRD data. Since only a very slight lattice expansion of $\mathrm{CZ}$ is observed, the $\mathrm{Ce}^{4+} / \mathrm{Ce}^{3+}$ red-ox pair is locked and Pd cannot be maintained in the oxidized state for a long time, in stark contrast to the fresh and thermally aged catalysts. The similarity between the $\mathrm{CO}_{2}$ evolution of the three catalysts seems to indicate that the aging by $\mathrm{P}$ affects the $\mathrm{CZ}$ considerably more than the $\mathrm{Al}_{2} \mathrm{O}_{3}$ and, therefore, that either $\mathrm{P}$ deposits more selectively on $\mathrm{CZ}$ or that the $\mathrm{P}$ deposited on $\mathrm{CZ}$ more strongly affects the catalyst efficiency than that deposited on $\mathrm{Al}_{2} \mathrm{O}_{3}$. The latter is more likely as it hinders oxygen exchange by locking the $\mathrm{Ce}^{4+} / \mathrm{Ce}^{3+}$ pair as evident from XRD. Comparison between XRD and MS data clearly shows that in the $\mathrm{O}_{2}$ pulse $\mathrm{CO}_{2}$ evolution is associated with re-oxidation of both Pd and CZ. However, the $\mathrm{CO}_{2}$ maximum is probably attributable to removal of adsorbed $\mathrm{CO}_{2}$ since the $\mathrm{CO}_{2}$ peak vanishes faster than oxidation takes place.

Finally, and similarly to the case of $\mathrm{Rh}, \mathrm{CO}_{2}$ production is maximized at the $\mathrm{O}_{2} \rightarrow$ CO switch, when clearly Pd changes from oxidized to reduced, therefore indicating that an oxide layer is present when highest activity is obtained.

\section{Conclusions}

Concentration modulated excitation (cME) and phase sensitive detection (PSD) have been used to demonstrate the sensitivity enhancement that can be introduced in XAS and high energy XRD compared with conventional measurement approaches. Small dynamic structural changes have been followed with greatly enhanced sensitivity in two case studies where hydrothermal aging and chemical treatment of model three-way catalysts have been considered. In the case of $2 \mathrm{wt} \% \mathrm{Rh} / \mathrm{Al}_{2} \mathrm{O}_{3}$ subjected to a CO-NO modulation experiment at $573 \mathrm{~K}$, cMEED-XAS reveals that a fraction of $\mathrm{Rh}$ after reduction at $573 \mathrm{~K}$ responds to the external red-ox stimulation. The state of $\mathrm{Rh}$ is largely reduced in the fresh catalyst and in that aged at $973 \mathrm{~K}$ and fluctuates between slightly re-oxidized and reduced. In the fresh catalyst, it seems plausible that the environment of the active sites includes partially oxidized Rh nano-particles. After hydrothermal aging at $1273 \mathrm{~K}$, the catalyst is constantly oxidized. However, PSD is able to confirm that a small fraction of Rh is still able to perform NO reduction by $\mathrm{CO}$, although the catalyst selectivity is poor. Therefore, the extent of Rh oxidation and the nature of oxidized $\mathrm{Rh}$ species may play a crucial role in selectivity.

In the case of $1.6 \mathrm{wt} \% \mathrm{Pd} / \mathrm{Al}_{2} \mathrm{O}_{3}-\mathrm{Ce}_{1-x} \mathrm{Zr}_{x} \mathrm{O}_{2}$, the cME-XRD experiment was aimed at determining the effect of thermal aging and chemical treatment (by phosphorous) on the oxygen exchange capability of the catalyst and the structural changes involved in such a process. The preliminary results indicate that thermal aging already deteriorates the oxygen exchange properties of the catalyst because the fresh catalyst was able to maintain Pd oxidized for a longer time than the aged one. In this complex catalyst for XRD, PSD showed that deeper and unique insight in the structural dynamics can be obtained. The Pd nano-particles were identified in the catalyst and it was possible to tentatively discriminate between Pd deposited on $\mathrm{Al}_{2} \mathrm{O}_{3}$ and on ceria-zirconia. Moreover, very small lattice parameter variations were identified by PSD which point to the high sensitivity of the method.

All the discussed structural dynamic changes and the corresponding kinetics are difficult to resolve without the use of PSD. The increased sensitivity of the two traditionally bulk methods used in this work demonstrates that the combination of a pulsedtype experiment and PSD provides an exceptional means to study a range of materials which may previously have been regarded as intractable as a result of extremely subtle but nonetheless critical, structural variations. The method seems to be particularly powerful in the case of XRD that can provide a complete snapshot of the catalyst under reaction conditions with unprecedented resolution for this technique and for complex systems. Finally, we should mention that application of ME and PSD as described here is straightforward from an experimental viewpoint. As demonstrated in some studies, including this one, PSD can be performed on various data sets. Hence, various aspects of the structure of a solid catalyst, along with many other functional materials at work can be potentially characterized with improved sensitivity with respect to conventional approaches.

\section{Acknowledgements}

The authors kindly acknowledge PSI, Empa, the Competence Center for Materials Science and Technology (CCMX), VSS lubes, the Erdöl-Vereinigung, the Federal Office for the Environment, Erdgas Mobil and Umicore for financial support, and ESRF for allocating beam time at beamlines ID24 and ID15B. Ms Y. Lu, Ms O. Korsak, Dr A. Eyssler, Dr D. Zurita and Dr J. Andrieux are acknowledged for support during the measurements.

\section{References}

1 J. D. Grunwaldt, M. Caravati, S. Hannemann and A. Baiker, Phys. Chem. Chem. Phys., 2004, 6, 3037.

2 M. A. Newton, M. Di Michiel, A. Kubacka and M. FernandezGarcia, J. Am. Chem. Soc., 2010, 132, 4540.

3 A. M. Beale and B. M. Weckhuysen, Phys. Chem. Chem. Phys., 2010, 2010, 5562 . 
4 P. Norby and J. C. Hanson, Catal. Today, 1998, 39, 301.

5 P. J. Chupas, K. W. Chapman, H. L. Chen and C. P. Grey, Catal. Today, 2009, 145, 213.

6 M. A. Newton, K. W. Chapman, D. Thompsett and P. J. Chupas, J. Am. Chem. Soc., 2012, 134, 5036.

7 P. Canton, C. Meneghini, P. Riello and A. Benedetti, in In situ spectroscopy of catalysts, ed. B. M. Weckhuysen, American Scientific Publisher, Stevenson Ranch, California, 2004, p. 293.

8 M. A. Newton and W. van Beek, Chem. Soc. Rev., 2010, 39, 4845.

9 A. I. Frenkel, J. A. Rodriguez and J. G. Chen, ACS Catal., 2012, 2, 2269.

10 A. Martorana, G. Deganello, A. Longo, A. Prestianni, L. Liotta, A. Macaluso, G. Pantaleo, A. Balerna and S. Mobilio, J. Solid State Chem., 2004, 177, 1268.

11 J. D. Grunwaldt, N. van Vegten and A. Baiker, Chem. Commun., 2007, 4635.

12 M. A. Newton, M. Di Michiel, A. Kubacka and M. FernandezGarcia, J. Am. Chem. Soc., 2010, 132, 4540.

13 W. van Beek, O. V. Safonova, G. Wiker and H. Emerich, Phase Transitions, 2011, 84, 726.

14 D. Baurecht and U. P. Fringeli, Rev. Sci. Instrum., 2001, 72, 3782.

15 D. Ferri, M. Santhosh Kumar, R. Wirz, A. Eyssler, O. Korsak, P. Hug, A. Weidenkaff and M. A. Newton, Phys. Chem. Chem. Phys., 2010, 12, 5634.

16 T. Bürgi and A. Baiker, J. Phys. Chem. B, 2002, 106, 10649.

17 A. Urakawa, T. Bürgi and A. Baiker, Chem. Phys., 2006, 324, 653.

18 I. Dolamic and T. Bürgi, J. Catal., 2007, 248, 268.

19 D. Ferri, M. A. Newton and M. Nachtegaal, Top. Catal., 2011, 54, 1070.

20 A. Eyssler, E. Kleymenov, A. Kupferschmid, M. Nachtegaal, M. Santhosh Kumar, P. Hug, A. Weidenkaff and D. Ferri, J. Phys. Chem. C, 2011, 115, 1231.

21 C. F. J. König, J. A. van Bokhoven, T. J. Schildhauer and M. Nachtegaal, J. Phys. Chem. C, 2012, 116, 19857.

22 W. van Beek, H. Emerich, A. Urakawa, L. Palin, M. Milanesio, R. Caliandro, D. Viterbo and D. Chernyshov, J. Appl. Crystallogr., 2012, 45, 738.

23 M. Santhosh Kumar, E. H. Otal, M. H. Aguirre, A. Winkler, A. Ulrich, D. Rentsch, A. Weidenkaff and D. Ferri, Catal. Today, 2012, 184, 237.

24 M. A. Newton, J. Synchrotron Radiat., 2007, 14, 372.

25 M. A. Newton, Top. Catal., 2009, 52, 1410.

26 T. Ressler, J. Synchrotron Radiat., 1998, 5, 118.

27 N. R. Collins and M. V. Twigg, Top. Catal., 2007, 42-43, 323.

28 K. C. Taylor, Catal. Rev. Sci. Eng., 1993, 35, 457.

29 P. Granger, F. Dhainaut, S. Pietrzik, P. Malfoy, A. S. Mamede, L. Leclercq and G. Leclercq, Top. Catal., 2006, 39, 65.

30 Z. Hu, F. M. Allen, C. Z. Wan, R. M. Heck, J. J. Steger, R. E. Lakis and C. E. Lyman, J. Catal., 1998, 174, 13.

31 K. Dohmae, Y. Nagai, T. Tanabe, A. Suzuki, Y. Inada and M. Nomura, Surf. Interface Anal., 2008, 40, 1751.
32 H. Hirata, K. Kishita, Y. Nagai, K. Dohmae, H. Shinjoh and S. Matsumoto, Catal. Today, 2011, 164, 467.

33 M. Cavers, J. M. Davidson, I. R. Harkness, L. V. C. Rees and G. S. McDougall, J. Catal., 1999, 188, 426.

34 J. L. Freysz, J. Saussey, J. C. Lavalley and P. Bourges, J. Catal., 2001, 197, 131.

35 M. A. Newton, C. Belver-Coldeira, A. Martinez-Arias and M. Fernandez-Garcia, Nat. Mater., 2007, 6, 528.

36 J. Stötzel, D. Lützenkirchen-Hecht, R. Frahm, B. Kimmerle, A. Baiker, M. Nachtegaal, M. J. Beier and J. D. Grunwaldt, J. Phys.: Conf. Ser., 2009, 190, 012162.

37 S. Chansai, R. Burch, C. Hardacre, J. Breen and F. Meunier, J. Catal., 2010, 276, 49.

38 M. Santhosh Kumar, O. Korsak, L. Bocher, D. Logvinovich, P. Hug, A. Weidenkaff and D. Ferri, Top. Catal., 2011, 54, 1213.

39 J. Kaspar, C. de Leitenburg, P. Fornasiero, A. Trovarelli and M. Graziani, J. Catal., 1994, 146, 136.

40 P. Araya, F. Gracia, J. Cortes and E. E. Wolf, Appl. Catal., B, 2002, 38, 77.

41 M. A. Newton, A. J. Dent, S. G. Fiddy, B. Jyoti and J. Evans, J. Mater. Sci., 2007, 42, 3288.

42 M. A. Newton, A. J. Dent, S. G. Fiddy, N. B. Jyoti and J. Evans, Catal. Today, 2007, 126, 64.

43 M. A. Newton, A. J. Dent, S. Diaz-Moreno, S. G. Fiddy, B. Jyoti and J. Evans, Chem.-Eur. J., 2006, 12, 1975.

44 J. Gustafson, R. Westerström, O. Balmes, A. resta, R. van Rijn, X. Torrelles, C. T. Herbschleb, J. W. M. Frenken and E. Lundgren, J. Phys. Chem. C, 2010, 114, 4580.

45 D. A. J. Michel Ligthart, R. A. van Santen and E. J. M. Hensen, Angew. Chem., Int. Ed., 2011, 50, 5306.

46 A. J. Dent, J. Evans, S. G. Fiddy, N. Jyoti, M. A. Newton and M. Tromp, Angew. Chem., Int. Ed., 2007, 46, 5356.

47 M. Lopez Granados, C. Larese, F. Cabello Galisteo, R. Mariscal, J. L. G. Fierro, R. Fernandez-Ruiz, R. Sanguino and M. Luna, Catal. Today, 2005, 107-108, 77.

48 L. Xu, G. Guo, D. Uy, A. E. O'Neill, W. H. Weber, M. J. Rokosz and R. W. McCabe, Appl. Catal., B, 2004, 50, 113.

49 S. Y. Christou, M. C. Alvarez-Galvan, J. L. G. Fierro and A. M. Efstathiou, Appl. Catal., B, 2011, 106, 103.

50 M. Santhosh Kumar, M. A. Newton, A. Weidenkaff and D. Ferri, Catal. Today, 2013, 205, 3.

51 M. A. Newton, M. Di Michiel, A. Kubacka, A. Iglesias-Juez and M. Fernandez-Garcia, Angew. Chem., Int. Ed., 2012, $\mathbf{5 1 ,} 2363$.

52 Z. Kaszkur, J. Appl. Crystallogr., 2000, 33, 1262.

53 W. Vogel, J. Phys. Chem. C, 2011, 115, 1506.

54 A. Benedetti, S. Polizzi, P. Riello, F. Pinna and G. Goerigk, J. Catal., 1997, 171, 345.

55 M. Shen, M. Yang, J. Wang, J. Wen, M. Zhao and W. Wang, J. Phys. Chem. C, 2009, 113, 3212.

56 R. Rajasree, J. H. B. J. Hoebink and J. C. Schouten, J. Catal., 2004, 223, 36.

57 M. Boaro, F. Giordano, S. Recchia, V. Dal Santo, M. Giona and A. Trovarelli, Appl. Catal., B, 2004, 52, 225. 